\title{
ReMed: Unterstützung und Hilfe in schwierigen Situationen
}

\author{
Ärztinnen und Ärzte sind beruflich stark gefordert - manchmal sogar überfordert. \\ Das Unterstützungsnetzwerk ReMed kennt die kritischen Situationen und Belastun- \\ gen des Arztalltags und zeigt Handlungsmöglichkeiten für die Ratsuchenden auf.
}

Mirjam Tanner ${ }^{\text {, }}$

Maximiliano Wepfer ${ }^{b}$

a Fachärztin für Psychiatrie und Psychotherapie, Leitungsausschuss ReMed

b Stv. Leiter Kommunikation $\mathrm{FMH}$

\section{Erfahrungsbericht}

Eine heute 48-jährige Fachärztin für Gynäkologie und Geburtshilfe aus einer mittelgrossen Westschweizer Stadt erinnert sich, wie der Stress des Praxisaufbaus ihre damals noch junge Familie beinahe auseinandersprengte:

«Gleichzeitig sowohl eine eigene Familie als auch eine eigene Praxis als noch junge und relativ unerfahrene Mutter, Ehefrau und Ärztin aufbauen - dies erwies sich bald nicht mehr nur als eine spannende Herausforderung, sondern auch als eine kräftezehrende Überforderung. Doch wenn man selber drinsteckt, kann man, wie so oft, den Kern der Probleme gar nicht erkennen. Vielmehr fanden mein Mann und ich uns irgendwann in einem derart destruktiven Beziehungspatt gefangen, dass wir beide zeitweise stark daran zweifelten, unser Leben gemeinsam bewältigen zu können.

Die Konflikte hatten angefangen, als unsere Söhne zwei und vier Jahre alt waren und ich meine

\section{«Jedenfalls ist es sehr gut, dass wir Ärztinnen auf die unkomplizierte Unterstützung von ReMed zählen können.»}

Korrespondenz:

Dr. med. Mirjam Tanner

mirjam.tanner[at]hin.ch erste Praxis frisch aufbaute. Mein Mann und ich arbeiteten beide sehr viel, weshalb ich nach dem ersten Jahr trotz des weiterlaufenden Aufbaus mein Arbeitspensum auf 50 Prozent reduzierte - eine Praxispartnerin kam hinzu. Die enorme Belastung führte zu sehr vielen Streitereien und verletzenden Auseinandersetzungen. Unsere Wohnsituation erlaubte uns nur beschränkt, uns aus dem Weg zu gehen, und so wurde unser Umgang miteinander immer zerstörerischer. Mein Mann war sehr verletzt, wenn ich mich nur mit Rückzug abgrenzen konnte.

Irgendwann beschlossen wir, eine Paartherapie zu beginnen. Diesem Schritt sah ich mit einer guten Portion Überheblichkeit entgegen; ich dachte, das würde ihm bestimmt guttun, und dann ginge es uns beiden wieder besser. Bereits nach zwei Sitzungen wies aber einiges darauf hin, dass ich auch meinen
Anteil an den Problemen hatte. Ich entschied mich, diese in einer eigenen Therapie anzuschauen. In deren Verlauf wurde mir klar, dass ich selber eine schwierige Vergangenheit mit meiner Mutter hatte. Aus diesem Grund war ich auch nicht in der Lage, weder zu mir selber noch zu meinem Mann und unserer Beziehung Sorge $\mathrm{zu}$ tragen. Entsprechend schlecht ging es mir: Ich war gerade dabei, aufgrund der Überforderung in der Familie und im Beruf meine eigene Ehe zu zerstören. Dies wollte ich verhindern, spürte aber gleichzeitig, dass ich es alleine nicht schaffte.

Ich fragte eine befreundete Kollegin aus meinem Qualitätszirkel, der ich sehr vertraue und die auch von unseren Ehekonflikten wusste, ob sie mir eine gute Psychiaterin empfehlen könne. Anschliessend beschloss ich, mich wie eine meiner eigenen Patientinnen zu überweisen und klarzustellen, dass es um mich selber geht, die eine Therapie beanspruchen möchte. Dass die Therapeutin mit Verständnis und Respekt, kompetent und dennoch auch kollegial auf meine Überweisung reagierte, war entscheidend dafür, dass ich mich auf sie einlassen konnte. Ausserdem nützte sicherlich das Eingeständnis, dass ich nicht immer alles alleine im Griff haben muss, dass es besser ist, zu einem gewissen Zeitpunkt Hilfe zu beanspruchen.

Wenn damals meine Freundin keine Psychiaterin gekannt oder ich gerade niemanden gehabt hätte, der bereits von meiner Lage wusste und dem ich vertrauen konnte, wäre ich sehr dankbar gewesen, mich an ReMed wenden zu können. Zusammen mit ReMed hätten sich eventuell auch Alternativen zu einer Psychotherapie ergeben. Jedenfalls ist es sehr gut, dass wir Ärztinnen auf die unkomplizierte Unterstützung von ReMed zählen können, wenn wir an unsere menschlichen Grenzen stossen.»

Befinden Sie sich in einer schwierigen Situation und suchen Rat? Oder benötigt ein Arzt, eine Ärztin in Ihrem Umfeld Unterstützung? Dann melden Sie sich bei ReMed über die 24-Stunden-Hotline 0800073633 oder über die Mail-Adresse help[at]swiss-remed.ch 